\title{
Ribeirinhos e recursos vegetais: a etnobotânica em Rondonópolis, Mato Grosso, Brasil
}

Riverine and plant resources: the etnobotany in Rondonópolis, Mato Grosso, Brazil

Messagers et les ressources végétales: un ethnobotanique en single

Rondonópolis, Mato Grosso, Brésil

Fluviales y recursos vegetales: la etnobotánica en solo en Rondonópolis, Mato Grosso, Brasil

\author{
Maria Corette Pasa* \\ Gabriela de Ávila**
}

Recebido em 12/12/2010; revisado e aprovado em 17/3/2010; aceito em 18/6/2010

\begin{abstract}
Resumo: Através da etnobotânica, o trabalho mostrou o conhecimento dos moradores locais quanto ao uso dos recursos vegetais nas hortas, quintais e matas de galeria do rio Arareau em Rondonópolis, MT. A metodologia se deu através de entrevistas semiestruturadas e não-estruturadas. Os resultados apontaram a etnocategoria medicinal sobre as demais. Relevância na interação das pessoas de saber local com o ambiente. A subsistência no local não proporciona impacto ambiental e favorece a conservação dos ecossistemas locais.
\end{abstract}

Palavras-chave: Etnobotânica. Recursos vegetais. Conservação.

Abstract: Through of etnobotany the work showed knowledge of local residents regarding the use of plant resources in home gardens, orchards and forests from river in Arareau Rondonópolis, MT. The methodology has come through semi-structured and no-structured interview. The results indicated the ethnocategory medicine over the other. Relevance in the interaction the people to know the local environment. The subsistence in the site no provide the environmental impact and promote the conservation in the local ecosystem.

Key-words: Etnobotany. Vegetable resources. Conservation.

Résumé: À travers de ethnobotanique de travail unique a montré la connaissance des résidents locaux concernant l'utilisation des ressources végétales dans les jardins potagers, des vergers et des forêts d'une rivière dans Arareau Rondonópolis, MT. La méthodologie est venu à travers semi-structurées en o-structurés. Le ethnocategory résultats apontararam un examen médical sur l'autre. Pertinence o clock dans l'interaction les personnes à connaître l'environnement local. L'horloge o subsistent dans le site $n$ fournit l'impact sur l'environnement èt favorise la conservation l'écosystème local.

Mots-clés: Ethnobotânica. Ressources végétales. Conservation.

Resumen: Através de etnobotánica el trabajo individual mostró conocimiento de los residentes locales sobre el uso de los recursos vegetales en los huertos familiares, pomares y bosques de río en Arareau Rondonópolis, MT. La metodología ha llegado através de las entrevistas semiestructuradas y noestructurada. El etnocategoría apontaram los resultados en la medicina popular sobre el otros. Reloj o relevancia en la interacción la gente a conocer el entorno local. El reloj o subsisten en el sitio no proporciona el impacto ambiental y promueve la conservacion Palabras clave: Etnobotánica. Recursos vegetales. Conservación.

\section{Introdução}

A etnobotânica desponta como um campo interdisciplinar que compreende o estudo e a interpretação do conhecimento, significação cultural, manejo e usos tradicionais dos elementos da flora (CABALERRO, 1979). A interação entre a antropologia, a etnoecologia e a ecologia pode situar um cenário de investigação dentro da etnobiologia através do conhecimento dos aspectos sociais, culturais, antropológicos e econômi$\cos$ da sociedade.
Segundo Begossi (2001), a etnobiologia é "um segmento da etnociência, que busca entender como o mundo é percebido, conhecido e classificado por diversas culturas humanas $[\ldots]^{\prime \prime}$.

A partir da etnobiologia questões modernas da etnoecologia podem ser desenvolvidas e concentradas na proposta que diz respeito à totalidade de informações sobre a importância das plantas na cultura do ser humano. A integração se dá através da comunidade e do ambiente no que diz respeito ao manejo e a conservação dos recursos naturais (POSEY, 2001).

\footnotetext{
* Professora do Departamento e Ciências Biológicas/UFMT. E-mail: pasamc@brturbo.com.br ** Bióloga e Especialista em Ciências Ambientais/IB/UFMT.
} 
Em muitos casos, sistemas tradicionais de manejo altamente adaptados a ecossistemas específicos caíram em desuso, seja pela introdução da economia de mercado, pela desorganização ecocultural, seja por substituição por outros sistemas chamados "modernos" impostos de fora das comunidades (DIEGUES, 2001).

Porém, cada vez mais é necessário resgatar esses sistemas de manejo, pois ainda hoje são praticados por essas populações e, já se sabe que essas técnicas contribuem significativamente para a manutenção da diversidade biológica. Além disso, a esmagadora cultura global, o capitalismo, aos poucos, tende a dissipar essa riqueza que o homem construiu de modo tão simbiótico com o meio ambiente que está ao seu redor.

A cultura e o ambiente estão intimamente ligados. "Compreender a cultura de um povo expõe a sua normalidade" afirma Geertz (1989) e declara, ainda, que "a cultura é tratada de modo puramente como sistema simbólico [...] pelo isolamento dos seus elementos, especificando as relações internas entre esses elementos e passando então a caracterizar todo o sistema de uma forma geral".

Trata-se de decifrar os fenômenos que modelam a relação entre a ação, o pensamento e o que é falado, expressos pelo modo de agir sobre o ambiente e as transformações nele contidas. Ao analisar as dimensões simbólicas da ação social, vemos que a humanidade é tão variada em sua essência como em sua expressão, pelas formas de cultura e regularidades estruturais e funcionais da organização social.

O ambiente natural pode direta ou indiretamente afetar as condições sociais e a experiência humana. Da mesma forma, as condições sociais podem afetar o meio natural e a própria experiência humana. De acordo com o conceito de Ecologia Humana, a dinâmica entre o ser humano e a natureza, sob os aspectos bióticos, físicos, sociais e culturais do seu ambiente, não podem ser fragmentados, pois enfraqueceria a própria ciência (DIEGUES, 2001).

Para o presente estudo, os dados foram obtidos através de revisão de literatura e aplicação do pré-teste, que teve por objetivo selecionar as técnicas de pesquisa mais adequadas aos objetivos propostos, entre elas: (1) questionário socioeconômico, (2) registro fotográfico, (3) história de vida (ocupação da área), (4) entrevistas, do tipo semiestruturada e não-estruturada.

Assim, esse trabalho objetivou caracterizar os recursos vegetais das matas de galeria, hortas e quintais através de estratégias etnoecológicas e etnobotânicas para verificar o conhecimento que os moradores locais possuem a respeito da flora local, em Rondonópolis, MT, através: a)caracterizar a variabilidade da flora utilizada pela população ribeirinha verificando a importância do patrimônio genético das matas de galeria, hortas e quintais; b)verificar as formas de manejo de extração e utilização de espécies vegetais oriundas das diferentes unidades de paisagem (matas, hortas e quintais); c)interpretar a relação do ser humano com o ambiente, em uma visão etnobotânica, com base no histórico das características socioculturais e econômicas da região como forma de verificar o grau de degradação ambiental.

\section{Desenvolvimento experimental}

\section{Coleta de dados com os informantes}

O presente trabalho é um estudo de cunho etnobotânico, em que foram coletados dados do uso tradicional de plantas pela população da parte alta do córrego Arareau. A hidrografia que drena o perímetro urbano de Rondonópolis é caracterizada por córregos como o Arareau e o Rio Vermelho, que fazem parte da bacia do Rio São Lourenço, que desagua no Pantanal, delimitados pelas coordenadas geográficas de $54^{\circ} 30^{\prime} 00^{\prime \prime}$ a $54^{\circ}$ $39^{\prime} 00^{\prime \prime}$ de longitude oeste e $16^{\circ} 25^{\prime} 00^{\prime \prime}$ a $16^{\circ}$ $30^{\prime} 00^{\prime \prime}$ de latitude sul. O clima caracterizado pelo tropical úmido, com temperatura média anual de $25^{\circ}$ e a média das mínimas de $18,6^{\circ} \mathrm{C}$. A temperatura ultrapassa os $26^{\circ} \mathrm{C}$ nos meses de setembro e outubro, compreendendo o período mais quente, e o mais frio, junho e julho, que fica em torno dos $22^{\circ} \mathrm{C}$ (SETTE, 2001).

Os informantes foram selecionados, de início, ao acaso e, posteriormente, conforme indicação das pessoas já entrevistadas, de acordo com o conhecimento sobre plantas ou, ainda, com o tipo de produção desen- 
volvida em sua propriedade, o que resultou num total de 42 pessoas entrevistadas alocadas em 22 pontos que determinam a área de estudo.

Para a aquisição e caracterização dos dados socioeconômicos, foi utilizado um questionário e, posteriormente seguiram-se entrevistas do tipo semiestruturada e nãoestruturada (MINAYO, 1994). Assim, se deu mais importância às preocupações e ênfases dos informantes sem perder a informação necessária. Conforme a orientação da entrevista sobre a comunidade, muitos informantes partiram para a história oral, que é essencialmente uma história da vida, transmissão de fatos, testemunho (MEYHY, 1996). Também foi utilizado o registro fotográfico para obtenção de dados relacionados ao ambiente.

Coleta do material botânico

A coleta consistiu na obtenção de plantas inteiras (no caso, herbáceas de pequeno porte) ou de partes das plantas (no caso de espécies arbóreas, arbustivas e subarbustivas) tais como folhas, ramos, parte de caule, flores, frutos, sementes e raízes. Para a concretização da coleta foram utilizados instrumentos básicos de campo, como: tesoura de poda, facão e canivete, sacos plásticos e uma ficha de coleta. Após identificação, o material botânico foi depositado no Herbário Central da UFMT em Cuiabá.

\section{Resultados e discussão}

Através do pré-teste, abordou-se: sexo, idade, estado de origem, grau de instrução, tempo que reside no local e atividade que desempenha atualmente. Um total de 42 pessoas foram entrevistadas, representando a unidade amostral. Dessas, 54,76\% (23 informantes) são do sexo feminino e $45,24 \%$ (19 informantes) do sexo masculino. Todos os informantes trabalham em sua propriedade, seja para obter alimento para seu próprio sustento, seja para comercializar. A idade dos informantes femininos variou de 20 a 65 anos e a dos masculinos de 21 a 70 anos.

Quanto ao nível de escolaridade, $16,67 \%$ (sete informantes) possuem o primário completo e $9,52 \%$ (quatro informantes) possuem o ensino fundamental completo. Com o ensino médio incompleto e completo somam um total de $16,67 \%$ (sete informantes), dos quais são pessoas jovens de até 35 anos e são moradores novos da região. Com nível superior, foram $14,29 \%$ (cinco informantes), sendo quatro moradores novos e um informante do sexo masculino, morador tradicional que nasceu e cresceu no local. A Tabela 1 mostra o cruzamento dos dados da forma de apropriação e o tempo de residência no local. Do universo amostral de 22 famílias, 9,09\% (duas famílias) são proprietárias e residem no local em torno de 30 anos e $4,45 \%$ (uma família) não é proprietária, mas reside há 27 anos na mesma chácara. Os que estão a menos de 14 anos no local representam a maioria, sendo 9,09\% (duas famílias) não proprietários e 77,27\% (17 famílias) sendo proprietários.

Tabela 1 - Dados sobre a forma de apropriação da propriedade e o tempo no local.

\begin{tabular}{lccc}
\hline & Mais de 15 anos no local & Menos de 14 anos no local & Total \\
\hline Proprietários & $2(9,09 \%)$ & $17(77,27 \%)$ & 19 \\
Não proprietários & $1(4,45 \%)$ & $2(9,09 \%)$ & 3 \\
\hline Total & $\mathbf{3}$ & $\mathbf{1 9}$ & $\mathbf{2 2}$ famílias \\
\hline
\end{tabular}

O resultado acima retrata a grande evasão do campo para cidade já visto também por Pasa (2007), nas comunidades do Bambá em Cuiabá/MT, a fim de se integrar no modo de vida da cidade. Também mostra a chegada de imigrantes de diversas regiões do país trazendo outras culturas, formas de pensar e integrando ainda mais o capitalismo na região. 


\section{Recursos vegetais utilizados pela população local: As unidades de paisagens}

Os quintais e as roças

Nos sistemas de quintais há várias espécies de plantas que são cultivadas junto com outras culturas, além da presença de animais (galinhas, porcos e gado) que podem ser utilizados tanto para o próprio sustento como para um pequeno comércio, que é realizado, ou na frente das próprias residências, ou nas feiras da cidade de Rondonópolis. A maioria dos quintais se localiza na parte de trás da residência, como foi verificado também por Pasa (2004); há espaço para a demanda familiar com cultivo quase sempre de verduras e hortaliças, plantas medicinais e frutíferas. As hortas presentes são pequenas, apenas para própria subsistência da família e sem a utilização de agrotóxicos. $\mathrm{Na}$ maioria das vezes, com presença de cebolinha, alface, coentro, couve e rúcula. Ao produzir alimentos para a subsistência da família, o quintal exerce considerável papel econômico na vida dessas pessoas e, em se tratando de hortas grandes, consiste na única fonte de renda. A mão-de-obra é predominantemente familiar: pai, mãe e filhos. Nos fundos das casas, predomina o cultivo de um pequeno pomar que atende à demanda familiar. Podemos referir aos pomares como hortos caseiros por possuírem espécies frutíferas de vários tipos, vindos muitas vezes de várias regiões do país, que servem como complemento para a alimentação da família. A roça, também uma unidade de paisagem, foi verificada em vários trabalhos como uma área de manejo de cultura da cana-de-açúcar, mandioca, banana, entre outros (PASA, 2004). Na parte alta da bacia do rio Arareau, foram poucas as pessoas que alegaram possuir roça. Apenas duas famílias possuem plantação de mandioca (Manihot esculenta) para a produção de farinha.

O quintal, além de ser uma unidade de paisagem alimentar, com sua diversidade alimentar, ornamental e medicinal, como as principais encontradas na Comunidade Globo Recreio, também é uma unidade de paisagem para a socialização. As crianças usam o local para desenvolverem suas brincadei- ras; e jovens e adultos desfrutam do local para receber amigos, fazer reuniões, festas e convívio familiar. De acordo com Geertz (1989), a cultura é vista pelo sistema simbólico, que nada mais é que a própria ação social, ou mais simplesmente as palavras. Então podemos entender que os quintais não são meras unidades de paisagens, mas locais que as pessoas utilizam como meio cultural.

As plantas perenes, além de promoverem o sombreamento do quintal, também promovem uma melhor infiltração da água na terra, colaborando para a formação de matéria orgânica. Existe sempre grande variedade de espécies com poucos exemplares, colaborando para um baixo índice de doenças e pragas. Apesar de existirem poucos exemplares de cada espécie de planta, moradores locais alegaram plantar no mínimo duas árvores de cada qualidade, pois os animais da mata, como os macacos, na época da seca, vão comer os frutos que estão no pomar (habitat de borda). Isso porque a mata de galeria está cada vez menor, devido à ação do desmatamento. A riqueza vegetal encontrada nos quintais das casas e na mata de galeria que faz fundo com o terreno foi de 137 espécies. As etnocategorias de uso refletem as necessidades básicas de cada família, como alimentação e medicinais, sendo as principais, seguidas por madeireira, ornamentação, mística e utensílios. Essa grande variedade de plantas reflete a in fluência cultural que a região recebeu dos diversos "novos" moradores.

Das 137 espécies utilizadas pela população 31,39\% (43 espécies) são nativas da região, as quais continham exemplares nos próprios quintais ou nas matas de galeria da margem do córrego Arareau. Uma porcentagem de 57,66 (79 espécies) é de origem exótica, remanejadas ou introduzidas em locais destinados para o consumo ou utilização para algum fim específico, e desse total 10,95\% (15 espécies) não foram identificadas.

Se analisarmos a flora mato-grossense sob o ponto de vista econômico, com certeza encontraremos um rol muito extenso das diferentes utilizações dos vegetais, seja como elementos fornecedores de madeira, de frutos comestíveis e mesmo com finalidades medicinais, essencialmente na utilização 
caseira como pode ser detectado entre a população mato-grossense que comumente faz uso das plantas medicinais (GUARIM NETO, 1996).

\section{A etnobotânica nas matas de galeria}

O Cerrado destaca-se por ser o segundo bioma em extensão territorial constituído por uma série de formações vegetais muito ricas do ponto de vista botânico (REZENDE, 1998). A formação do Cerrado que se associa aos cursos d'água é chamada de mata de galeria, mata ciliar ou mata ripária. Essa formação destaca-se pela sua riqueza, diversidade genética e papel protetor aos recursos hídricos e da natureza (COUTINHO, 1978).

Populações de saber local desenvolveram uma interessante relação com a mata. Dela retiram alimento, através da atividade de coleta de frutos, e caça e pesca de animais, remédios para diversos tipos de doenças, madeira para construções de casas ou usada como lenha, e ainda, como atividade recreativa.

As pessoas que vivem na comunidade Globo Recreio utilizam mais a mata de galeria à procura de remédios e recreação nas águas do rio Arareau, onde recebem amigos e familiares da cidade. Assim, além das atribuições de coleta, caça e pesca, o rio com sua mata também é uma unidade de paisagem onde as pessoas se socializam. As diversas espécies vegetais existentes na região são muito úteis no cotidiano da população. Uma espécie pode ter mais de uma utilização, com caráter cumulativo, como alimentar, medicinal e ornamental. Essa multiplicidade de uso pode aumentar conforme a quantidade de partes da planta utilizada, como raiz, caule, folha, flor, fruto e semente. Os informantes referiram seis categorias de uso: alimento, remédio, ornamental, madeireira, lenha e utensílios quanto à utilização da plantas descritas na Tabela 7. Observou-se que a atividade de coleta de produto florestal não se constitui como atividade primordial e sim como uma atividade complementar, principalmente, no conhecimento do ecossistema e do uso que a população faz das ervas medicinais. Isso foi verificado também por Pasa et al. (2005).

\section{As plantas medicinais utilizadas e a abordagem etnoecológica}

Verificou-se que há um frequente número de espécies envolvidas nas práticas medicinais. As mesmas plantas podem ser usadas para mais de uma enfermidade, enquanto várias espécies podem ser usadas separadamente ou em combinação para tratar uma dada doença. A escolha da ou das espécies dita uma mistura de experiência e crença. Grande parte das plantas citadas possui multiplicidade de uso, ou seja, é destinada a várias utilidades. Com maior frequencia, 88 citações foram para fins alimentícios, e para remédios para diversos tipos de doenças, 69 indicações. Esses remédios manifestam sua importância na fitoterapia local sob o ponto de vista econômico (figura 1).

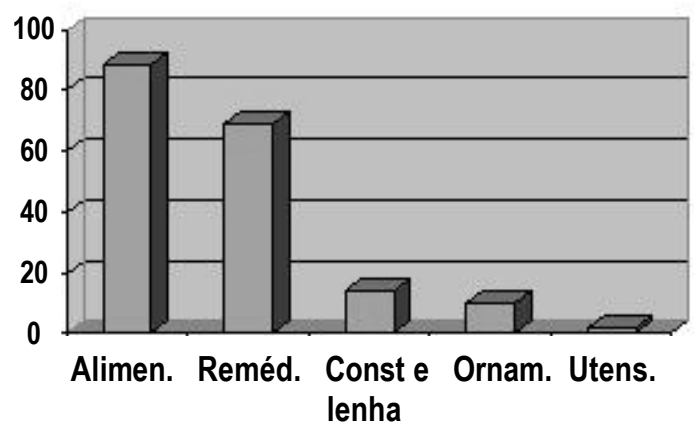

Quantidade citada

Figura 1 - Categorias de uso e número das plantas utilizadas pela população local.

O uso medicinal popular é muito importante para pessoas da zona rural, uma vez que o atendimento médico encontra-se distante, além do elevado custo para muitos medicamentos. O Sr. O. L. G. (63 anos), em um depoimento, relatou que, quando novo, machucou a coluna e, de teimosia, pela cidade ser muito longe na época, não foi ao 
médico, passados alguns meses nem conseguia andar.

Curei minha coluna com sucupira. Pega um metro de casca com $3 \mathrm{~cm}$ de espessura, tem que ser o lado que o sol nasce, pica, coloca na água e deixa cozinhá até virá um melado na medida de uma colher de sopa. Coloca num litro de vinho e toma um cálice toda manhã com o estômago vazio. Foi assim que melhorei da coluna e nunca mais tive nada.

Outra planta citada várias vezes e que só é encontrada na beira do rio é o jenipapo, cujo suco do fruto, segundo um informante, é excelente para diminuir os efeitos colaterais da quimioterapia. As outras etnocategorias de uso foram pouco citadas, sendo a madeira para construção de casas, paiol, cercas e lenha com 14 citações, ornamentação com 10 e as plantas que possuem alguma parte que pode servir de utensílio com duas citações (figura 2).

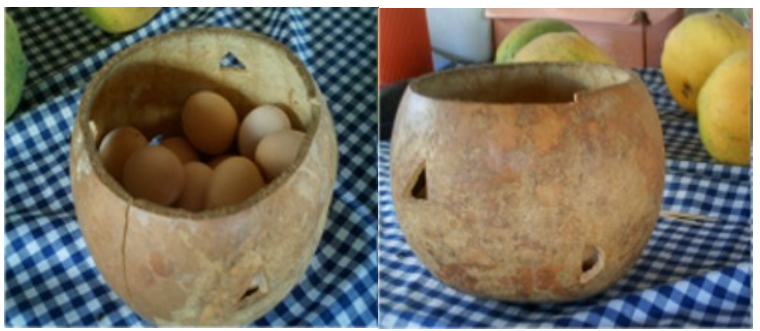

Figura 2 - Fruto seco do coité utilizado como vasilhame.

Foto: Gabriela de Ávila. 2007.

Em relação às plantas usadas pela comunidade local, evidenciou-se que as partes da planta usadas e as indicações de uso são relevantes no tratamento das afecções orgânicas que acometem o ser humano, conforme demonstra a Figura 3 e Tabela 2.
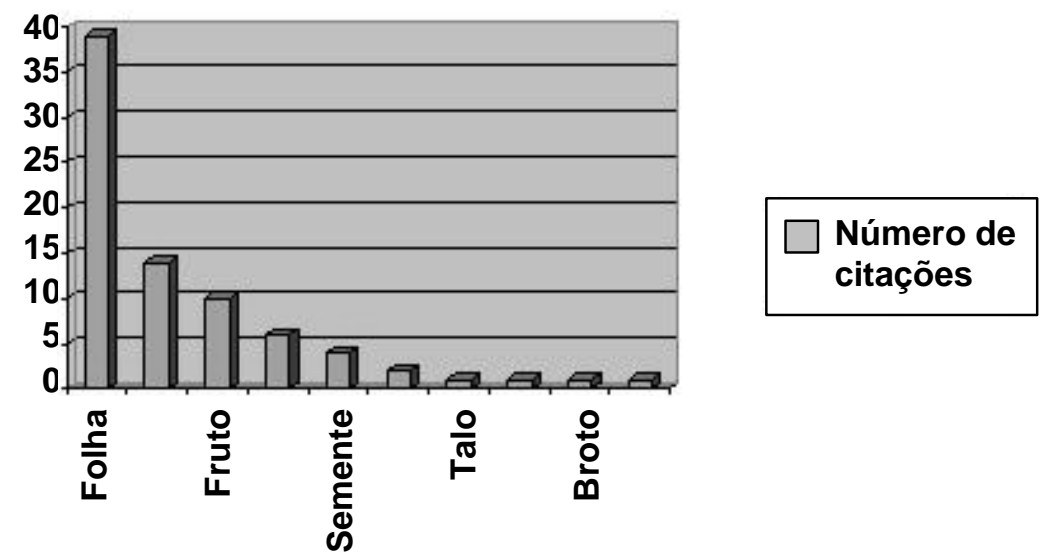

Figura 3 - Partes das plantas utilizadas com fins medicinais pela população local.

Pasa (1999) verificou que, no entendimento e no depoimento dos informantes, a ação terapêutica das plantas medicinais visa combater os sintomas (que são subjetivos) e os sinais (que são visíveis) parcial ou totalmente iguais ou comuns entre as pessoas locais.

O uso das folhas para preparo dos medicamentos pela população foi o que obteve maior utilização, 40 citações, seguida pelo uso da casca do tronco e do fruto, com 14 e
10 citações respectivamente. As outras partes utilizadas das plantas obtiveram citação inferior a sete, as quais foram: raiz, semente, seiva, talo cipó, broto e óleo. Verificou-se que as pessoas não utilizam apenas as partes de uma planta, mas o que ela produz, como a seiva, o óleo e o próprio endosperma, esse último quando se tratando do coco-da-bahia, em que as pessoas utilizam a água contida em seu interior para tratar a desidratação e como energético, entre outras utilidades. 
Tabela 2 - Plantas dos quintais usadas como remédio. Rondonópolis, MT.

\begin{tabular}{|c|c|c|c|c|}
\hline Nome Cientifico & Tome Ptpular & Parte Usada & Prepano & Indicaçăo Terapếutica \\
\hline Cuscirbita pepo L. & Abóbora & Semente & Chá & Vemúfigo \\
\hline Gos sypizm herbaceum L & Algodão & Flor & Chá & Irflamação do útero e ovínos \\
\hline Antemisia absinthium L. & Áternjje & follha & Chá & Febre, dor de cabeça \\
\hline Rita graveolens L. & Amida & Follha & Chá & Abortivo \\
\hline Vemonia feruginea Less & Assa peixe & Follha & Infuxão & Diurético, dor na bexiga \\
\hline Alloe vera $\mathrm{L}$. & Babosa & Sumo & inf์1são & Úloera, gastrite \\
\hline Soleus barbatus Berth & Boldo & Follha & Chá & Indizestão, tontura \\
\hline Vemonia polianthes L. & Caferana & Folla & Chá & Lavar fenidas \\
\hline Matricaria recutita L. & Camomila & Ramo foliax & Chá & Constipação intestinal \\
\hline Cymbopogumatratus L. & Capimcidreira & follha & Chá & Calmarte \\
\hline Tacarandá semisemata $\mathrm{C}$. & Carob inla & follha & chá & Úloera, gastrite \\
\hline Bacchay trimera Less. & Carqueja & Folha & Chá & Indigestão, tontura \\
\hline Alprina speciosa Schum & Colônia & Flor & banhode asserto & Cólicas de b aixo verthe, pressão alta \\
\hline Symplytum oficinale L. & Confrei & Follha & Chá & Úloera,gastrite \\
\hline Lippia alba (Mill.) Bhume & Erva cidreira & follha & Chá & Gripe, calmarte \\
\hline Polygonomacre H B.K & Erra de bicho & Follha & Compressa & Hemomcida, varizes \\
\hline Eusalyptus sp & Eucalipto & Follha & Chá & Tosse, gripe \\
\hline Cássia occidentale L. & Fedegoso & Raiz & Maoerada & Tôrrico nusculare fadiga \\
\hline Zingiber oficinalis Rosc. & Genglbre & Bulbo & Chá & Gripe dor de gargarta \\
\hline Petiveria alliacea $\mathrm{L}$. & Guiné & Follha & Chá & Febre, gipe \\
\hline Mentha pipenta $\mathrm{L}$. & Hortelã & Follha & Chá & Vemúfigo \\
\hline $\begin{array}{l}\text { Stachytopheta augustifolia } \\
\text { Lopez-Palacios }\end{array}$ & Gerrão & Follha & Chá & Indigestão \\
\hline Solanum aft?ycocaprum St. Hil. & Jumbeba & Follha & Chá & Problemas do figado \\
\hline Citrus limonam Osbeck. & Limão & Sumo & Suco & Press̃̃o alta \\
\hline Passiflora edulis Sims. & Maracujá & Follha & Chá & Calmarte \\
\hline Achyrocline saturecides DC & Maosla & Folha & Chá & Indizestão, azia \\
\hline Chenopotium ambnusoides L. & Mastouz & folla & Chá & Vemúfugo, machucadura \\
\hline Mentha pule giom L. & Poejo & Follha & Chá & Febre, gipe \\
\hline Phyllanthes orbicubas M. Arg. & Quebra-pedra & Follha & Chá & Inflamação dos rims \\
\hline Punica granation L. & Romã & Casca & Chá & Inflamação da gargarta \\
\hline Sambses rigra L. & Sabugueiro & Follha & Chá & Febre, tosse \\
\hline Smilax sp & Salsaparillka & Raiz & Chá & Reumatismo \\
\hline Colocasia sp & Taioba & Follha & Chá & Depurativo do sargue \\
\hline ¿ycopersicum esculentum Mill & Tomate & Follha & Chá & Diứtico \\
\hline Bactris glascescens Drude & Tucum & Fruto & Chá & Vemrífugo \\
\hline Scopariadulcis L. & Vassourimba & Follha & Enplastro & Machucaduras, quebraduras \\
\hline
\end{tabular}

Entre as plantas usadas como remédio verificou-se que a maior frequência destinase ao tratamento de problemas referentes ao aparelho digestivo (26\%), como auxiliares de digestão, prisão de ventre, diarreia, estômago e fígado. Seguido pelas afecções ocasionadas por infecção e parasitas $(25 \%)$, sistema nervoso $(12 \%)$, sistemas circulatório e uriná- rio ( $8 \%$ cada) e sistemas tegumentar, genital e respiratório com $6 \%$ cada um.

Além de contribuir para expressar a importância dos quintais no cotidiano das pessoas da região, o levantamento das plantas medicinais serve para contribuir com a lista das espécies que, segundo Amorozo e Gely (1988), servem para subsidiar pesquisas 
farmacológicas pelas quais muitas plantas usadas pela população cabocla já tiveram comprovação farmacológica em estudos de laboratório como o caso do mastruz (Chenopodium ambrosioides) e do pião roxo (Jatropha gossypiifolia).

Também foram encontradas nos quintais das casas algumas plantas com funções "protetora", "mal olhado" e "olho grande" de proteção pessoal, entre elas a guiné, a arruda, a espada-de-são-jorge e comigo-ninguém-pode. Para Amorozo e Gely (1988), a utilização das plantas para proteção pessoal e de uso tópico para fins curativos e mágicos refere a um legado indígena associado à influência europeia. Os banhos protetores podem estar relacionados a uma parte do corpo, como também no corpo inteiro, ou banhos para "curar" a pessoa de algum mal que a acomete. Assim, no Brasil atual, sobrevivem sistemas de crenças diversas, provenientes de culturas que integram a formação social brasileira, como africana e indígena.O simbolismo é expresso no conhecimento que a população detém sobre o uso popular de plantas com função protetora, como são denominadas de "jurema" que, segundo Mota e Albuquerque (2002),

[...] jurema é portanto mais que uma planta: é representação, divindade, mulher e vinho. Assim sendo, todo um conjunto de crenças se lhe encontra associado. As plantas denominadas jurema ocupam, com efeito, um papel destacado na flora nordestina pela referencia mágico-religiosa [...]. A jurema penetrou na cultura popular estando associada à figura de índios, caboclos e mestres, elementos presentes no imaginário popular $[\ldots]$.

No cenário mato-grossense, Pasa (2007) refere-se à guiné (Petiveria alliacea), sendo esta planta indicada para espantar maus espíritos, inveja e mau-olhado. Também a espada-de-são-jorge, arruda, alho, café e farinha de mandioca para fazer banho do "corpo todo" e defumação da casa.

Quanto à utilização das plantas como medicinais, as formas de uso estão relacionadas ao porte das plantas, tamanho das folhas, estado fenológico, a quantia de indivíduos existentes no local e a parte a ser utilizada. O uso das plantas medicinais, como o chá, através da utilização das folhas, obteve a maior quantidade de citações, 44 , enquanto as outras formas de uso, tais como infusão, banho, garrafada, ao natural, compressa, aplicação local, banho de assento e macerado, em conjunto, obteve um total de 36 citações.

\section{O saber tradicional e a transmissão do conhecimento ecológico tradicional}

Os conhecimentos acumulados e as culturas dos povos tradicionais nos revelam que é o resultado de uma evolução conjunta, a longo prazo, das sociedades e de seu meio natural, conforme Lévêque (1999).

A principal forma de transmissão do conhecimento é o oral, que é feita de forma simples, no dia-a-dia, conforme a situação que estão vivendo, não há nada escrito ou livros. Na maioria das vezes, os pais, avós ou membros da mesma família fazem a transmissão oral, no interior do próprio grupo doméstico. Crianças e adolescentes acompanham os mais velhos nas tarefas cotidianas e, então, o saber tradicional é compartilhado dentro dessa cultura e transmitido de geração em geração, adquirindo o teórico e o prático, ao mesmo tempo, por absorção das explicações verbais e codificações (mitos e crenças). Porém, vários entrevistados relataram que a geração mais jovem não se interessa pelo conhecimento e experiência dos mais velhos.

Nota-se a presença de outro processo de transmissão de conhecimento em que pessoas vindas de outras culturas, ou seja, de outras regiões, compartilham seus conhecimentos, verificado no exercício das medicinas populares. Caballero (1998) afirma que muitas vezes o conhecimento etnobotânico quebra barreiras interculturais. Isso é notado pelos relatos de diferentes informantes "aprendi isso com um senhorzinho que passou por aqui" ou ainda "isso quem me falou foi um raizeiro que veio coletá planta aqui".

Na margem do córrego Arareau, especialmente nos finais de semana, as famílias e os amigos se reúnem para a prática de atividades de lazer. "Estas práticas proporcionam momentos espontâneos de aprendizado sobre o ambiente circundante" (XAVIER, 2005). Jovens e adultos utilizam dessa maneira para a socialização dos conhecimentos sobre os recursos vegetais. 
Além disso, a investigação dos espaços sociais nos quais a transmissão deste conhecimento é realizada pode ser um foco específico da pesquisa, que venha revelar o complexo fenômeno de socialização do conhecimento tradicional na localidade. (XAVIER, 2005).

\section{As populações tradicionais e a conservação da biodiversidade}

A busca de um melhor e racional aproveitamento dos recursos naturais e a conservação de suas milenares culturas e tradições vem contribuir para um melhor aproveitamento do meio natural. Lévêque (1999) confirma que os conhecimentos e as culturas tradicionais podem contribuir para a conservação, a longo prazo, da biodiversidade dos ecossistemas. Isso conduz a interessar-se pela diversidade cultural, ela também está fortemente ameaçada pela mundialização dos modelos culturais dominantes.

Primack e Rodrigues (2001) afirmam que as áreas onde há grande diversidade biológica são as regiões onde há maior diversidade cultural. O estado de Mato Grosso está numa região privilegiada de riqueza biológica, em pleno Cerrado do Brasil Central, com suas matas de galeria ricas em diversidade. Porém, o modelo capitalista, dominante no mundo, cada vez mais destrói e deixa poucos remanescentes naturais e encurrala os povos tradicionais, forçando-os muitas vezes a agirem contra a própria natureza.

Muitas populações nativas que utilizam a mata para caça e coleta perderam suas terras para a criação de unidades de conservação com modelos norte-americanos. Diegues (2001) afirma que esse modelo não permite a presença de populações humanas, mesmo as consideradas tradicionais que habitavam essas áreas por dezenas e até centenas de anos sem a depredarem. Quando a população tradicional daquele ambiente é retirada e proibida de utilizar da natureza o seu sustento, elas muitas vezes são capazes de violar as fronteiras da nova unidade ou se revoltam e começam a utilizar o ambiente de forma destrutiva o que resulta em confrontos com os administradores.

Felizmente essa realidade está mudando, cada vez mais naturalistas se conscientizam de que as populações tradicionais aju- dam a preservar a reserva. Isso contribui para a manutenção de exemplos dinâmicos de relação harmoniosa entre homem e natureza para as sociedades urbano-industriais, segundo Diegues (2001).

Lévêque (1999) diz ainda que esta contribuição do meio florestal é importante nos países em desenvolvimento, uma vez que esses alimentos são bens gratuitos e não aparecem nas contas das famílias. Se a riqueza cultural está relacionada com a diversidade biológica, por que não utilizar do conhecimento dos povos tradicionais que evoluem junto com o meio natural, muitas vezes, há centenas de anos para conservar, preservar, ou mesmo restaurar aquele meio natural?

As pessoas que vivem dos modos tradicionais, mesmo com a invasão da cultura capitalista, não perdem sua essência, o respeito à natureza. A demonstração da consciência sobre o desmatamento, perda da diversidade, a importância dos rios, das chuvas e da terra são diversos.

Numa parte da área de estudo, a coleta de lixo não é realizada, na qual o Sr. M. O. P reside. Ali é percebida a grande consciência de conservação. Um dos buracos antigos de mineração foi deixado aberto para colocar o lixo produzido na chácara. O lixo orgânico é utilizado como adubo natural na horta, as latinhas e garrafas pet são separadas para reciclagem e o restante colocado no buraco e, desse modo a chuva não leva para dentro do rio. É evidente a interação das pessoas locais com os ecossistemas, bem como o exercício cotidiano do processo de conservação na região.

\section{Referências}

ALBUQUERQUE, Ulysses. P. Introdução à etnobotânica. 2. ed. Rio de Janeiro: Interciência, 2005.

ALMEIDA, Cecilia F. C. B. R.; ALBUQUERQUE, Ulysses. P. Uso e conservação de plantas e animais medicinais no estado de Pernambuco (Nordeste do Brasil): um estudo de caso. Interciência, v. 27, n. 6, p. 277-285, jun. 2002.

AMOROZO, Maria Cristina. de M.; GELY, Antonio. Uso de plantas medicinais por caboclos do Baixo Amazonas. Barcarena, PA, Brasil. Bol. Mus. Pará Emílio Goeldi, Sér.Bot. 4, p. 47-131, 1988.

BEGOSSI, Alpina. Resiliência e populações neotradicionais: os caiçaras (Mata Atlântica) e os caboclos (Amazônia, Brasil). In: DIEGUES, Antonio Carlos; MOREIRA, André de Castro (Orgs.). Espaços e recursos 
naturais de uso comum. São Paulo: NUPAUB, 2001. p. 205-231.

CABALLERO, Javier. Floristic varation in modern Maya homegardens: ethnobiological implications. In: GÓMEZ-POMPA, A. (ed.). Homegardens of the Maya area. [S.1.]: West View Press, 1979. (In Press).

COUTINHO, Leopoldo M. O conceito de cerrado. Revista Brasileira de Botânica, (1), p. 17 -23, 1978.

DIEGUES, Antonio C. O mito moderno da natureza intocada. 3. ed. São Paulo: HUCITEC, 2001.

FRIEDMAN, John. A Preliminary classification of the Healing Potential of Medicinal Plants, Base don a Rational Analysis of Ethnopharmacological Field Survey Among Bedouins in the Negev Desert, Israel. Journal of Ethnopharmacology, v. 16, p. 275-287, 1986.

GEERTZ, Clifford. A interpretação das culturas. Rio de Janeiro: LTC, 1989.

GUARIM NETO, Germano. Plantas medicinais do estado do Mato Grosso. Brasília: ABEAS/UFMT, 1996.

LÉVÊQUE, Chistian. A biodiversidade. Bauru, SP: EDUSC, 1999.

MEIHY, José C. S. B. Manual de história oral. São Paulo: Loyola, 1996.

MINAYO, Maria C.S. O desafio do conhecimento: pesquisa qualitativa em saúde. São Paulo: Hucitec; Rio de Janeiro: Abrasco, 1994.

MOTA, Clarice N.; ALBUQUERQUE, Ulysses P. (Org.). As muitas faces da Jurema: de espécie botânica à divindade afro-indígena. Recife: Bagaço, 2002.

PASA, Maria C. Um olhar etnobotânico sobre as comunidades do Bambá. Cuiabá, MT: Entrelinhas, 2007.

. Etnobiologia de uma comunidade Ribeirinha no Alto da Bacia do Rio Aricá Açu, Cuiabá, Mato Grosso, Brasil. 2004. Tese (Doutorado em Ecologia e Recursos Naturais) - Centro de Ciências Biológicas e da Saúde, Universidade Federal de São Carlos, São Carlos-SP, 2004.

A utilização dos recursos vegetais no Vale do Aricá, Mato Grosso: um estudo etnoecológico. 1999. Dissertação (Mestrado em Ecologia e Conservação da Biodiversidade) - Instituto de Biociências, Universidade Federal de Mato Grosso, Cuiabá, 1999.

PASA, Maria C.; GUARIM-NETO, Germano. Plantas medicinais no Vale do Aricá, município de Cuiabá, estado de Mato Grosso, Brasil. Biodiversidade, 1(4), p. 10-27, 2006.
- Garrafadas medicinais de plantas de Mato Grosso (I): Anemopaegma arvense (Vell.) Stellf. e $A$. glaucum Mart. Ex DC. Biodiversidade, 1(4), p. 28-38, 2005. Talisia subalbens (Martius) Radlkofer (Sapindaceae): Espécie endêmica do cerrado de Mato Grosso. Biodiversidade 1(3), p. 42 - 48. 2004.

PASA, Maria C.; SOARES, João J.; GUARIM-NETO, Germano. Estudo etnobotânico na comunidade de Conceição-Açu (alto da bacia do rio Aricá-Açu, MT, Brasil). Acta Botanica Brasílica, São Paulo, v. 19, n. 2, p. 195-207, 2005.

POSEY, Darrel A. Interpretando e utilizando a "realidade" dos conceitos indígenas: o que é preciso aprender dos nativos? In: DIEGUES, Antonio Carlos; MOREIRA, André de Castro (Orgs.). Espaços e recursos naturais de uso comum. São Paulo: NUPAUB, 2001.

PRIMACK, Roberto P.; RODRIGUES, Everaldo. Biologia da conservação. Londrina: Midiograf, 2001.

RAPPAPORT, Roy A. Natureza, cultura e antropologia ecológica. In: SHAPIRO, H. L. Homem, cultura e sociedade. São Paulo: Martins Fontes, 1982. p. 251-282.

REZENDE, Alba V. Cerrado: Matas de galeria. In: RIBEIRO, J. F. (Ed.). Importância das matas de galeria: manutenção e recuperação. Planaltina: EMBRAPACPAC, 1998. p. 3-16.

RIBEIRO, José F. (Ed.). Cerrado: matas de galeria. Planaltina: Embrapa - CPAC, 1998.

SETTE, Denise M.; TARIFA, João R. Clima e ambiente urbano tropical: o caso de Rondonópolis-MT. In: Revista INTERGEO, (1), p. 26-35, 2001.

SILVA-ALMEIDA, Maria de F.; AMOROZO, Maria. C. M. Medicina popular no distrito de Ferraz, município de Rio Claro, estado de São Paulo. Brazilian Journal of Ecology, Rio Claro-SP, n. 2, p. 36-46, 1998.

VIERTLER, Renate B. Estudos de ecologia cultural em grupos tribais amazônicos: perspectivas. In: NEVES, W. A. Biologia e ecologia humana da Amazônia: avaliação e perspectivas. Belém, PA: SCT/PA CNPq - Museu Paraense Emílio Goeldi, 1989. (Coleção Eduardo Galvão).

Seminário de etnobiologia e etnoecologia do Sudeste. In: AMOROZO et al. (Ed.). Métodos antropológicos como ferramenta para estudos em etnobiologia e etnoecologia. Rio Claro, SP: SBEE, 2002. p. 11-29.

XAVIER, Fernando. F. Conhecimento ecológico tradicional e recursos vegetais em Nossa Senhora da Guia, Cuiabá, Mato Grosso. 2005. Dissertação (Mestrado em Ecologia e Conservação da Biodiversidade) - Instituto de Biociências, Universidade Federal de Mato Grosso, Cuiabá, 2005. 